\title{
Flora da Bahia: Juncaceae
}

\section{Ana Maria Giulietti ${ }^{1,2^{*}}$, Carla Teixeira de Lima $a^{1, a}$, Márcio Lacerda Lopes Martins ${ }^{3, b}$, Daniela Santos Carneiro-Torres $^{1, \mathrm{c}} \&$ Reyjane Patricia de Oliveira ${ }^{1, \mathrm{~d}}$}

${ }^{1}$ Programa de Pós-graduação em Botânica, Departamento de Ciências Biológicas, Universidade Estadual de Feira de Santana, Feira de Santana, Bahia, Brasil.

${ }^{2}$ Instituto Tecnológico Vale de Desenvolvimento Sustentável, Belém, Pará, Brasil.

${ }^{3}$ Centro de Ciências Agrárias, Ambientais e Biológicas, Universidade Federal do Recôncavo da Bahia, Cruz das Almas, Bahia, Brasil.

Resumo - É apresentada aqui a flora de Juncaceae do estado da Bahia, Brasil. São reconhecidas quatro espécies de Juncus: J. densiflorus, J. marginatus, J. micranthus e J. microcephalus. Este é o primeiro registro de J. marginatus no Nordeste; a espécie era conhecida apenas da Região Sul. São apresentados chave de identificação, descrições, ilustrações, comentários gerais e mapas de distribuição das espécies na Bahia.

Palavras-chave adicionais: Brasil, florística, Juncus, Poales, taxonomia.

Abstract (Flora of Bahia: Juncaceae) - The flora of Juncaceae from Bahia State, Brazil, is presented here. Four species of Juncus are recognised: J. densiflorus, J. marginatus, J. micranthus and J. microcephalus. This is the first report of J. marginatus in the Northeast Brazil; the species was previously known only from the South. An identification key, descriptions, illustrations, general notes and distribution maps of species in Bahia are provided.

Additional key words: Brazil, floristics, Juncus, Poales, taxonomy.

\section{JUNCACEAE}

Ervas anuais ou perenes, geralmente rizomatosas; rizoma ascendente ou horizontal, nós curtos, cobertos ou não por escamas; caules aéreos eretos, ou raramente procumbentes ou ascendentes, cilíndricos ou raramente comprimidos lateralmente. Folhas alternas, basais ou dispostas ao longo do caule, com lâmina dorsiventral ou cilíndrica, bainha aberta (Juncus L.) ou fechada (Luzula DC.). Inflorescências terminais ou laterais, geralmente em antelas e multifloras, raramente unifloras (Distichia Nees \& Meyen, Oxychloe Phil., Patosia Buchenau e Rostkovia Desv.), subtendidas por 1 ou 2 brácteas membranáceas. Flores com (0)1-4 bractéolas, bissexuadas, actinomorfas, trímeras, homoclamídeas; tépalas externas 3, tépalas internas 3, livres, iguais ou subiguais, sepaloides; estames 3-6; ovário súpero, 3-carpelar, 1-3-locular, estigmas 3, placentação parietal ou axilar, com vários óvulos (Juncus) ou 3 óvulos, cada qual correspondendo a um carpelo, e placentação basal (Luzula). Frutos cápsulas com deiscência loculicida (Juncus, Luzula e Rostkovia) ou circuncisa (nos outros gêneros); sementes numerosas, distribuídas na placenta parietal ou axilar, ou três sementes basais, testa lisa ou ornamentada.

Juncaceae é uma família de Poales (APG IV 2016) que inclui oito gêneros e cerca de 450 espécies

\footnotetext{
*Autora para correspondência: anagiulietti@hotmail.com;

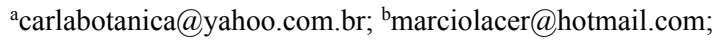

cdscarneiro@hotmail.com; ${ }^{d}$ rpatricia@uefs.br

Editor responsável: Alessandro Rapini

Submetido: 24 nov. 2017; aceito: 16 dez. 2017

Publicação eletrônica: 28 dez. 2017; versão final: 13 abr. 2018
}

(Záveská Drábková \& Kirschner 2013; Christenhusz \& Byng 2016). Os gêneros mais representativos são Juncus, com cerca de 300 espécies, e Luzula, com cerca de 115 espécies, ambos com distribuição cosmopolita (Kirschner 2002a,b,c); os demais gêneros incluem entre uma e seis espécies cada: Oreojuncus Záv. Drábk. \& Kirschner está distribuído em áreas temperadas do hemisfério norte (Závesk0 Drábková \& Kirschner 2013); Oxychloe, Distichia e Patosia ocorrem especialmente nos Andes e outras áreas elevadas do hemisfério sul, da Colômbia até a Argentina; Marsippospermum Desv. é endêmico da Patagônia; e Rostkovia ocorre disjuntamente nos Andes do Equador, Chile, Bolívia e Argentina e na Nova Zelândia (Balslev 1996; Jones et al. 2007).

Estudos filogenéticos têm demonstrado que Luzula é monofilético, enquanto Juncus aparece dividido em dois clados, incluindo os demais gêneros da família (Jones et al. 2007; Záveská Drábková 2010; Záveská Drábková \& Kirschner 2013). No Brasil, ocorrem Juncus e Luzula (Groppo \& Pirani 2004; BFG 2015), mas apenas Juncus ocorre na Bahia. A anatomia floral de Juncus e Luzula foi detalhadamente estudada por Oriani et al. (2012), cuja terminologia é adotada nesta flora.

\section{Juncus L.}

Ervas rizomatosas, glabras. Caules aéreos eretos ou raramente procumbentes ou ascendentes. Folhas alternas, basais ou dispostas ao longo do caule, com lâmina cilíndrica ou dorsiventralmente achatada, septada (com aerênquima dividido por diafragmas transversais) ou não; bainha aberta. Inflorescências cimosas ou racemosas, geralmente em antelas, com 
duas brácteas, uma proximal e outra distal. Flores com ou sem 2 bractéolas; tépalas externas e internas lanceoladas, inteiras, região mediana estramínea, castanha ou esverdeada com margens hialinas, persistentes no fruto; estames 3-6, filetes achatados ou cilíndricos, anteras lineares ou oblongas; ovário séssil, 1-3-locular. Cápsulas com deiscência loculicida lateral ou apical; sementes numerosas, elipsoides, obovoides, oblongoides ou ovoides.

Segundo Balslev (1996), o gênero Juncus seria composto de 220 espécies, das quais 41 ocorrem na região Neotropical, mas cerca de 300 espécies foram referidas para o gênero mais recentemente (Kirschner $2002 b, c)$. No Brasil, são reconhecidas 21 espécies; três delas eram citadas para a Bahia (Valadares 2017) e uma está sendo aqui registrada pela primeira vez no estado.

\section{Chave para as espécies}

1. Folhas com lâmina dorsiventralmente achatada ....... 2. J. marginatus

1'. Folhas com lâmina cilíndrica.

2. Ervas cespitosas; 2-7 flores por inflorescência ......................................... 4. J. microcephalus

2'. Ervas não cespitosa; 20-40 flores por inflorescência.

3. Folhas com lâmina 75-90 cm compr.; inflorescências 18-22 cm compr.; bractéolas ca. 1,5 mm compr.; cápsulas ca. 2,5 mm compr. .............................. 1. J. densiflorus

3'. Folhas com lâmina 40-70 compr.; inflorescências 3-5 cm compr.; brácteolas ca. 2,5 mm compr.; cápsulas ca. $3 \mathrm{~mm}$ compr.

3. J. micranthus

1. Juncus densiflorus Kunth, Nov. Gen. Sp. (quarto ed.) 1: 238. 1815 [1816].

Figuras 1 e 2 .

Ervas não cespitosas; rizoma evidente, 3-6 $\mathrm{mm}$ diâm.; caule aéreo ereto, ca. $90 \mathrm{~cm}$ alt. Folhas com lâmina cilíndrica, 75-90 × 0,3-0,5(-0,8) cm, septadas, bainha $7-16 \mathrm{~cm}$ compr., terminando em duas aurículas. Inflorescências terminais em antelas, 18-22 cm compr.; bráctea 3-5 cm compr.; bractéolas 2, ca. 1,5 mm compr. Flores 20-30 por inflorescência; tépalas lanceoladas, região mediana castanha, margens hialinas, as externas ca. 3,0 mm compr., as internas ca. 2,5 mm compr.; estames 3. Cápsulas uniloculares, castanhas, ovoide-trígonas, apiculadas, ca. 2,5 $\mathrm{mm}$ compr., deiscência lateral; sementes elipsoides, ca. 0,5 mm compr., castanho-amareladas, reticuladas.

Juncus densiflorus distribui-se na América do Sul, desde os Andes da Venezuela e Colômbia até as planícies do Paraguai, Argentina, Brasil e Uruguai (Balslev 1996). No Brasil, é referida para as Regiões Nordeste (Bahia), Sudeste (Espírito Santo, Minas Gerais, Rio de Janeiro e São Paulo) e Sul (Paraná, Santa Catarina e Rio Grande do Sul) (Valadares 2017). G7: campo úmido. Coletada com flores em novembro.
Material examinado - Barra do Choça, 14'52'48”S, 40³4'12"W, nov. 1978, Mori et al. 11307 (CEPEC, NY).

Juncus densiflorus foi coletada uma única coleta na Bahia. A coleção Harley 26066, identificada como $J$. densiflorus nos herbários MO e NY! (identificador anônimo), trata-se de $J$. micranthus. Essas espécies podem ser distintas pelo porte maior de $J$. densiflorus (ca. $90 \mathrm{~cm}$ vs. $50-70 \mathrm{~cm}$ alt.), que apresenta inflorescências também maiores (18-22 cm vs. $3-5 \mathrm{~cm}$ compr.) e tépalas externas ultrapassando a cápsula (Figura 1C).

2. Juncus marginatus Rostk., De Junco: 38; tab. 2, fig. 3. 1801.

Figuras 2 e $3 \mathrm{~A}-\mathrm{C}$.

Ervas cespitosas; rizoma não evidente, ca. $2,5 \mathrm{~mm}$ diâm.; caule aéreo ereto, $50-60 \mathrm{~cm}$ alt. Folhas com lâmina achatada dorsiventralmente, (20-)30-40 × ca. 0,5 cm, não septada; bainha $8-9 \mathrm{~cm}$ compr., conduplicada, terminando em duas aurículas. Inflorescências terminais em antelas, 7-10 cm compr.; bráctea 4-8 cm compr.; bractéolas 2, ca. 1,5 mm compr. Flores 3-9 por inflorescência; tépalas oval-lanceoladas, região mediana castanha, margens hialinas, as externas ca. $3 \mathrm{~mm}$ compr., as internas ca. 2,8 mm compr.; estames 3. Cápsulas uniloculares, castanhas, orbiculares, apiculadas, ca. 1,8 mm compr., septos evidentes, deiscência apical; sementes elipsoides, ca. 0,5 mm compr., castanho-amareladas, reticuladas.

Juncus marginatus distribui-se do leste da América do Norte à Argentina (Balslev 1996). No Brasil, foi citada apenas para a Região Sul (Paraná, Santa Catarina e Rio Grande do Sul) por Valadares (2017), sendo este seu primeiro registro para o estado da Bahia e para a Região Nordeste. D6/7, J8: campo úmido. Coletada em flor nos meses de junho e outubro.

Material examinado - Caravelas, $17^{\circ} 37^{\prime} \mathrm{S}, 39^{\circ} 13^{\prime} \mathrm{W}$, out. 2000, Mattos Silva et al. 4252 (CEPEC, NY); Morro do Chapéu, $11^{\circ} 40^{\prime} \mathrm{S}, 41^{\circ} 00^{\prime} \mathrm{W}$, jun.1996, Harley et al. PCD 3112 (ALCB, CEPEC, HUEFS, K).

Diferencia-se facilmente das demais espécies de Juncus da Bahia por apresentar as folhas com lâmina achatada dorsiventralmente, enquanto as demais apresentam folhas com lâmina cilíndrica. Juncus marginatus era conhecida até então apenas da Região Sul. Sua ocorrência na Bahia representa um novo exemplo de disjunção entre a Chapada Diamantina (Morro do Chapéu) e a restinga (Caravela), padrão também encontrado em outras famílias de angiospermas (Giulietti \& Pirani 1988).

3. Juncus micranthus Schrad. ex E.Mey, Syn. Luzul.: 31.1823.

Figuras 3D-F e 5.

Ervas não cespitosas; rizoma evidente, 4-8 $\mathrm{mm}$ diâm.; caule aéreo ereto, $50-70 \mathrm{~cm}$ alt. Folhas com lâmina cilíndrica, $40-70 \times$ ca. $0,5 \mathrm{~cm}$, septada, septos pouco visíveis após herborização; bainha $3-13 \mathrm{~cm}$ compr., terminando em duas aurículas. Inflorescências 


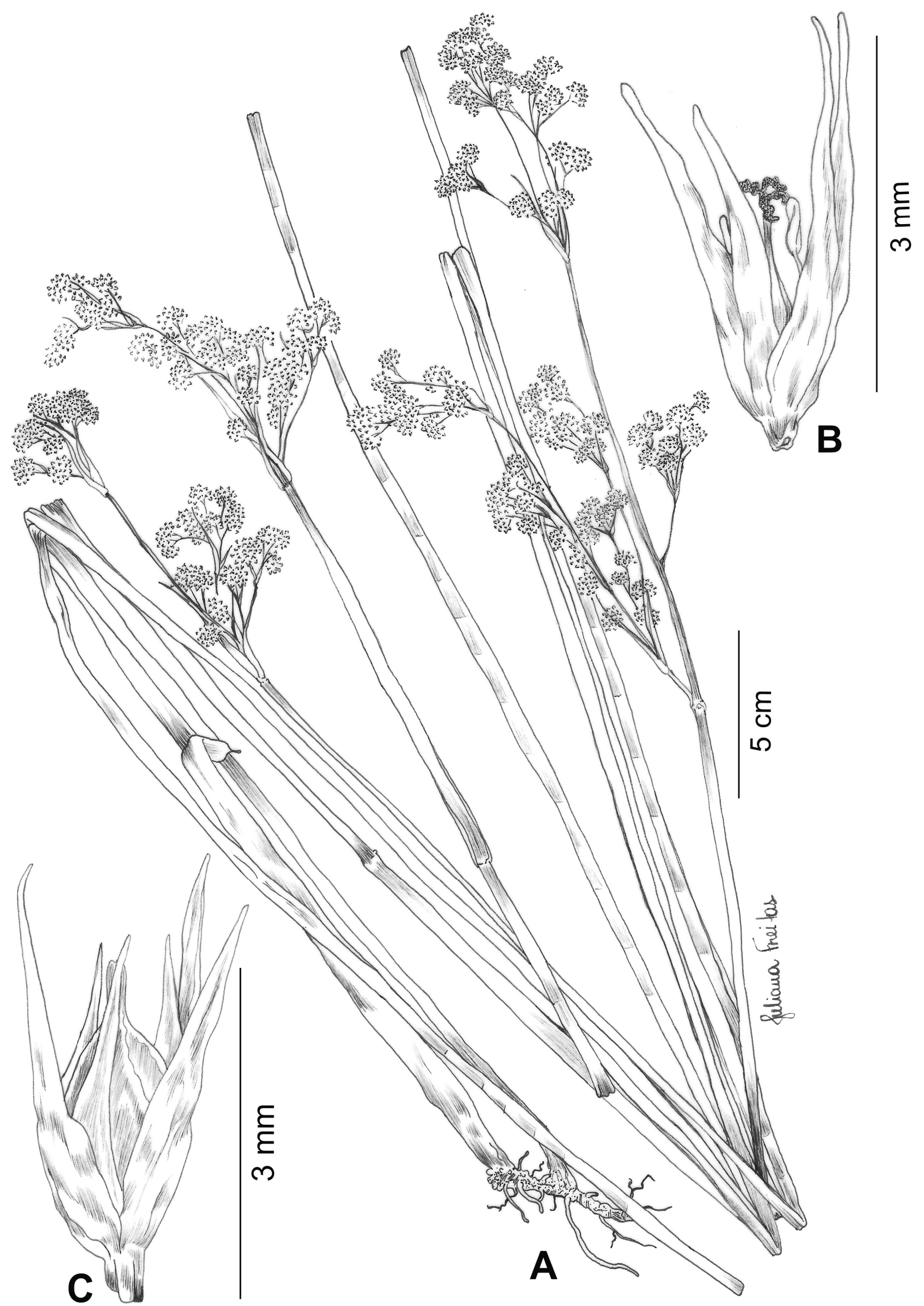

Figura 1. Juncus densiflorus: A- hábito; B- flor, mostrando as três tépalas externas, as três tépalas internas, os estames e o estigma; C- fruto com perigônio persistente (Mori 11307). 


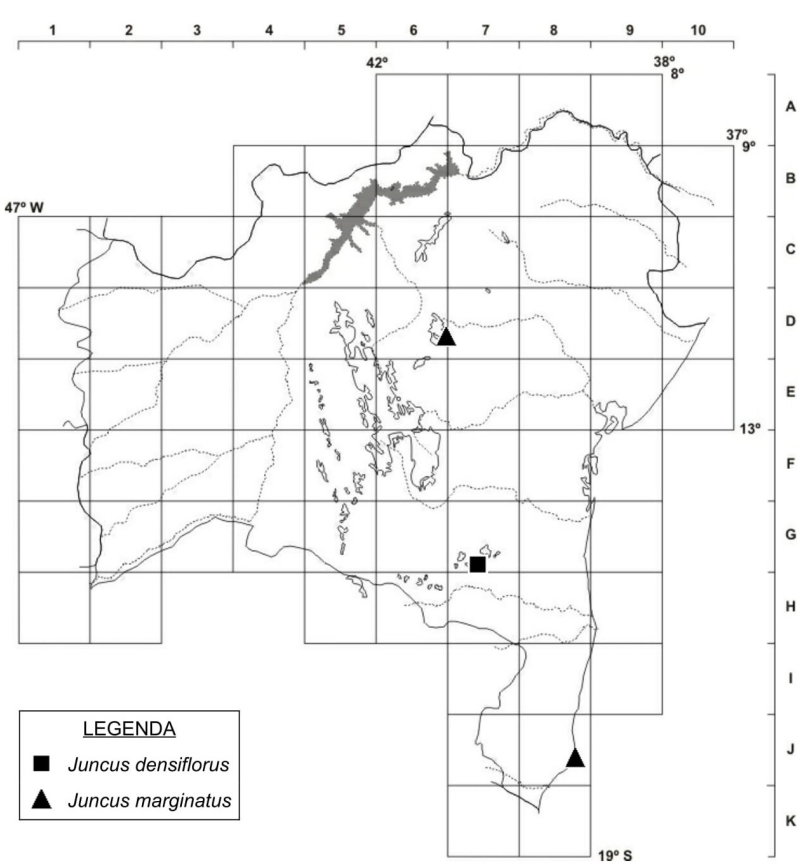

Figura 2. Distribuição geográfica de Juncus densiflorus e J. marginatus no estado da Bahia.

terminais em antelas, 3-5 cm compr.; bráctea 3-5 cm compr.; bractéolas 2, ca. 2,5 mm compr. Flores 25-40 por inflorescência; tépalas lanceoladas, região mediana castanha, margens hialinas, as externas ca. $3 \mathrm{~mm}$ compr., as internas ca. 2,8 mm compr.; estames 3 . Cápsulas uniloculares, castanhas, ovoide-trígonas, apiculadas, ca. $3 \mathrm{~mm}$ compr., deiscência lateral; sementes elipsoides, ca. 0,3 $\mathrm{mm}$ compr., castanhoamareladas, reticuladas.

Juncus micranthus distribui-se em áreas montanhosas do Brasil, do Sudeste até a Bahia, e áreas mais baixas no Paraguai, Argentina e Uruguai, com disjunção na Bolívia (Balslev 1996). No Brasil, é referida para o Centro-Oeste (Mato Grosso do Sul), Sudeste (São Paulo) e Sul (Paraná), em campo limpo. Balslev (1996) referiu a coleção Carvalho et al. 1061 (NY!) para Lençóis, mas a espécie não foi registrada para a Bahia por Valadares (2017). D6, E6, F6: Chapada Diamantina, em campos rupestres, geralmente acima de $1000 \mathrm{~m}$ de altitude, sobre solos úmidos. Floresce praticamente o ano inteiro, com maior intensidade de março a agosto.

Material selecionado - Abaíra, set. 1999, Conceição et al. 385 (HUEFS); Lençóis, dez. 1981, Carvalho et al. 1061 (CEPEC, NY);

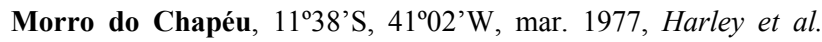
19214 (CEPEC); Mucugê, dez. 1979, Mori 13156 (CEPEC); Rio de

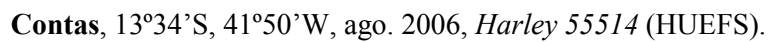

Juncus micranthus assemelha-se a $J$. densiflorus (veja o comentário daquela espécie). Os espécimes Harley 19214 (K) e 20044 (K) foram identificados como J. scirpoides Lam. por S. Mayo, e redeterminados por Balslev em 1981 sob J. micranthus. Balslev (1996) retirou J. scirpoides var. meridionalis Buchenau do status de variedade de $J$. scirpoides, uma espécie com distribuição concentrada nas áreas temperadas dos
Estados Unidos (Brooks \& Clemants 2000), mas também referida para o sul do Brasil (Valadares 2017), incluindo tal variedade na sinonímia de J. micranthus, posicionamento taxonômico adotado aqui.

4. Juncus microcephalus Kunth, Nov. Gen. Sp. (quarto ed.) 1: 237. 1815 [1816].

Figuras 4 e 5.

Ervas cespitosas; rizoma evidente, 1-4 mm diâm.; caule aéreo ereto, (30)50-100 cm alt. Folhas com lâmina cilíndrica, 70-90 × 0,3-0,5 cm, septadas; bainha 5-15 cm compr., terminando em duas aurículas. Inflorescências terminais em antelas, $15-30 \mathrm{~cm}$ compr.; bráctea 2-5(-10) cm compr.; bractéolas 2, translúcidas, ca. 1,5 mm compr. Flores (2 ou 3)5-7, tépalas lanceoladas, região mediana castanhoesverdeada, margens hialinas, as externas 2,5-3 mm compr., as internas ca. 2,5 mm compr.; estames 3 . Cápsulas uniloculares, castanhas, obovoides, apiculadas, ca. $2 \mathrm{~mm}$ compr., deiscência apical; sementes elipsoides a ovoides, ca. 0,5 mm compr., castanho-amareladas, reticuladas.

Juncus microcephalus ocorre em montanhas da região Neotropical, desde o México até a Bolívia (Balsev 1996). No Brasil, é citada para os estados da Bahia, Goiás, Minas Gerais, Rio de Janeiro e São Paulo, além do Distrito Federal (Valadares 2017). Na Bahia, ocorre na Chapada Diamantina, em altitudes acima de 1000 m (Simpson 1995). E6 e F6: campos rupestres, sobre solos úmidos. Floresce durante o ano todo.

Material selecionado - Ibicoara, Cascavel, $13^{\circ} 18^{\prime} \mathrm{S}, 41^{\circ} 50^{\prime} \mathrm{W}$, mar. 1999, Harley et al. 53581 (CEPEC, HUEFS, JPB); Mucugê, $12^{\circ} 57^{\prime} \mathrm{S}, 41^{\circ} 19^{\prime} \mathrm{W}$, jan. 2000, Jardim et al. 2541 (CEPEC); Palmeiras, $12^{\circ} 49^{\prime} \mathrm{S}, 41^{\circ} 31^{\prime} \mathrm{W}$, nov. 2007, Melo et al. 5359 (HUEFS); Piatã, $13^{\circ} 13^{\prime} \mathrm{S}, 41^{\circ} 45^{\prime} \mathrm{W}$, set. 1996, Harley et al. 28292 (HUEFS); Rio de Contas, 1336'S, 41 48 'W, set. 1998, Giulietti \& Harley 2529 (HUEFS); Seabra, Água de Rega, rodovia Km 27, 1000 m alt., Irwin et al. $31012(\mathrm{~K}, \mathrm{NY})$.

É uma espécie bastante variável morfologicamente, com porte de 20 a $100 \mathrm{~cm}$ de altura, (3-)10 a 35 flores por inflorescência (Balslev 1996) e número de estames variando de 3, 4 ou 6, até no mesmo indivíduo (Groppo \& Pirani 2004; Oriane et al. 2012). Na Bahia, os espécimes apresentaram alturas entre 50 e $100 \mathrm{~cm}$ e, consistentemente, 3 estames. Pode ser reconhecida pelas inflorescências bem desenvolvidas, com ramos que podem atingir até $30 \mathrm{~cm}$ de comprimento, e flores reunidas em grupos de 5 a 7 . O espécime Harley et al. $28292(\mathrm{~K})$ tem porte bem menor, cerca de $30 \mathrm{~cm}$ de altura, e inflorescências com apenas 2 ou 3 flores, mas a análise detalhada do material mostrou tratar-se de um espécime jovem.

\section{Agradecimentos}

Os autores agradecem à Juliana Freitas pelas ilustrações; aos curadores dos herbários consultados, 


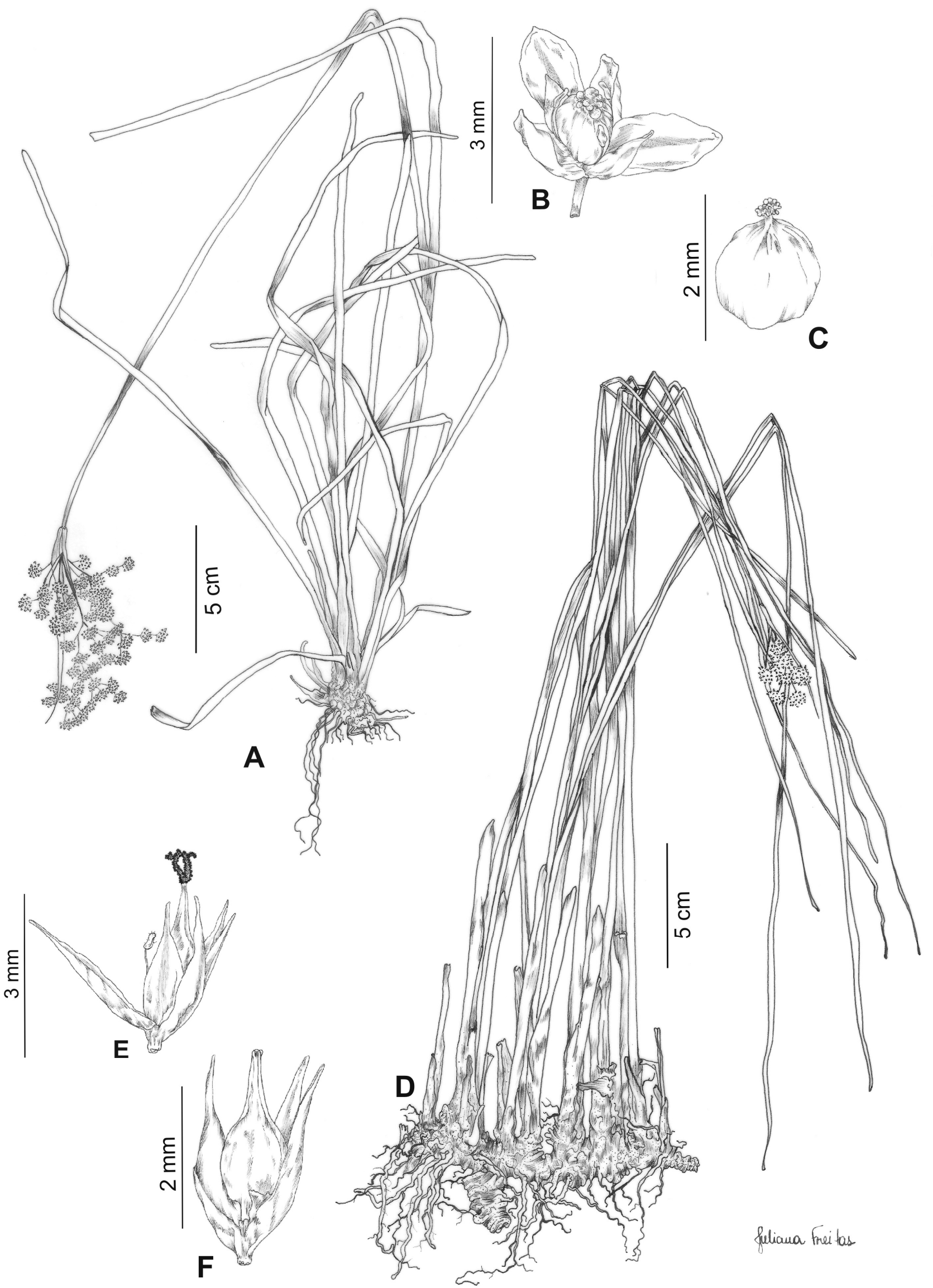

Figura 3. A-C. Juncus marginatus: A- hábito; B- flor, mostrando as três tépalas externas, as três tépalas internas e o ovário; C- fruto (Harley $P C D$ 3112). D-F. J. micranthus: D- hábito; E- flor, mostrando as três tépalas externas, as três tépalas internas, um estame e os estigmas. F- fruto com perigônio persistente (Harley 55514). 

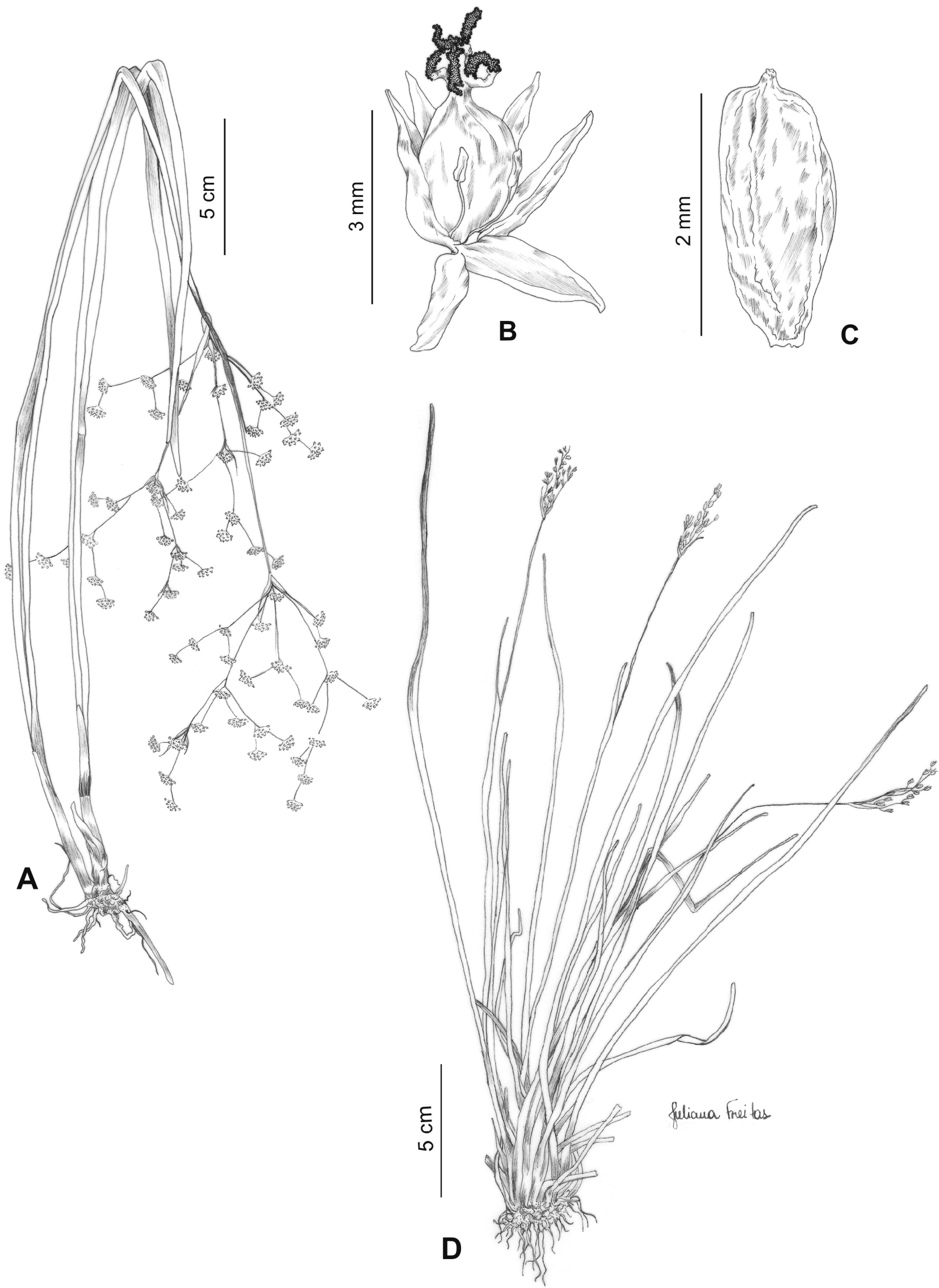

Figura 4. A-D. Juncus microcephalus: A- hábito; B- flor, mostrando as três tépalas externas, as três tépalas internas, os estames e o ovário; C- fruto (Giulietti 2529); D- hábito de um exemplar jovem (Harley 28292). 


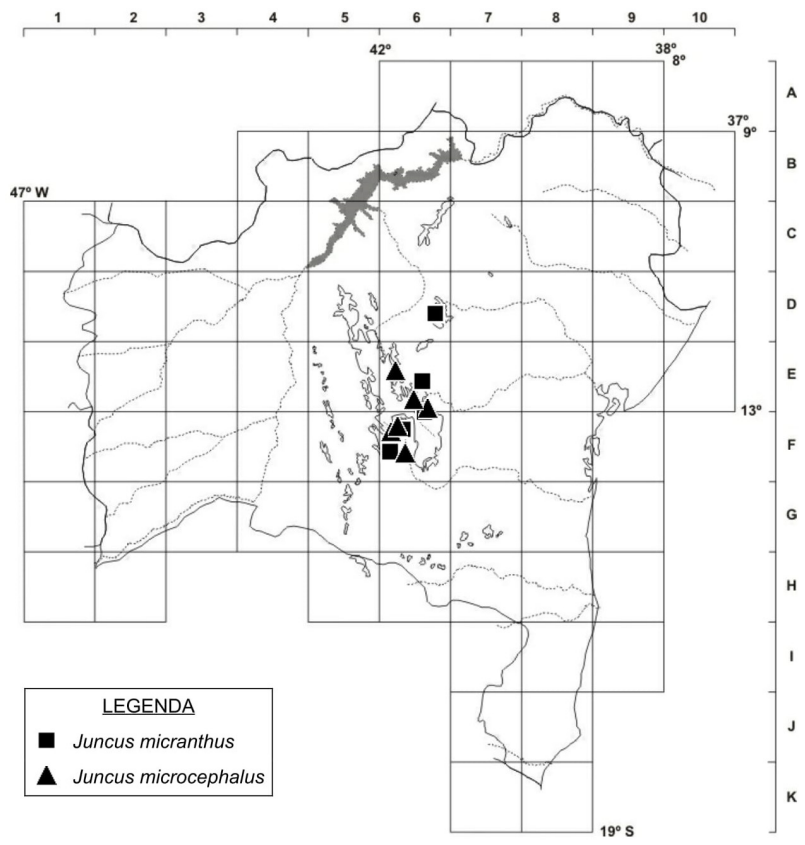

Figura 5. Distribuição geográfica de Juncus micranthus e J. microcephalus no estado da Bahia.

Especialmente ao HUEFS e ao CEPEC, pelo acesso às coleções; à FAPESB, pelo auxílio financeiro ao Projeto Flora da Bahia (APR0162/2007), e ao CNPq, pelo apoio ao PROTAX (562278/2010-9) e ao projeto Flora da Bahia (483909/2012-2). Ao CNPq, também, pelas bolsas de Produtividade em Pesquisa concedidas a AMG (PQ Senior) e RPO (PQ-1D).

\section{REFERÊNCIAS}

APG IV 2016. An update of the Angiosperm Phylogeny Group classification for the orders and families of flowering plants: APG IV. Botanical Journal of the Linnean Society 181: 1-20.

Balslev, H. 1996. Juncaceae. Flora Neotropica Monograph 68: 1167.

BFG (The Brazil Flora Group) 2015. Growing knowledge: an overview of Seed Plant diversity in Brazil. Rodriguésia 66: 1085-1113.

Brooks, R.E. \& Clemants, S.E. 2000. Juncaceae. In: Flora of North America Editorial Committee (eds), Flora of North America.
Vol. 22. Disponível em: www.eFloras.org; acesso em: 25 set. 2017.

Christenhusz, M.J.M. \& Byng, J.W. 2016. The number of known plant species in the world and its annual increase. Phytotaxa 261: 201-217.

Giulietti, A.M. \& Pirani, J.R. 1988. Patterns of geographic distribution of some plant species from the Espinhaço Range, Minas Gerais and Bahia, Brazil. In: P.E. Vanzolini, \& W.R. Heyer (eds), Proceedings of a Workshop on Neotropical Distribution Patterns. Academia Brasileira de Ciências, Rio de Janeiro, p. 39-69.

Groppo, M. \& Pirani, J.R. 2004. Flora da Serra do Cipó, Minas Gerais: Juncaceae. Boletim de Botânica da Universidade de São Paulo 22: 25-27.

Jones, E; Simpson, D.; Hodkinson, T.R.; Chase, M.W \& Parnell, J.A.N. 2007. The Juncaceae-Cyperaceae Interface: a combined plastid sequence analysis. Aliso 23: 55-61.

Kirschner, J. (org.) 2002a. Juncaceae 1: Rostkovia to Luzula. Species Plantarum: Flora of the World, Part 6. ABRS, Canberra, p. 1-237.

Kirschner, J. (org.) 2002b. Juncaceae 2: Juncus subg. Juncus. Species Plantarum: Flora of the World. Part 7. ABRS, Canberra, p. 1-326.

Kirschner, J. (org.) 2002c. Juncaceae 3: Juncus subg. Agathryon. Species Plantarum: Flora of the World. Part 8. ABRS, Canberra, p. 1-192.

Oriani, A.; Stutzel, T. \& Scatena, V.L. 2012. Contributions to the floral anatomy of Juncaceae (Poales - Monocotyledons). Flora 207: 334-340.

Simpson, D.A. 1995. Juncaceae. In: B.L. Stannard (ed.), Flora of the Pico das Almas-Chapada Diamantina, Bahia, Brazil. Royal Botanic Gardens, Kew.

Valadares, R.T. 2017. Juncaceae. In: Flora do Brasil 2020 (em construção). Jardim Botânico do Rio de Janeiro. Disponível em: http://floradobrasil.jbrj.gov.br/reflora/floradobrasil/F68082; acesso em: 15 nov. 2017.

Záveská Drábková, L. 2010. Phylogenetic relationships within Juncaceae: evidence from five regions of plastid, mitochondrial and nuclear ribosomal DNA with notes on morphology. In: O. Seberg, G. Petersen, A.S. Barford \& J.I. Davis (eds), Diversity, Phylogeny and Evolution in the Monocotyledons. Aarhus University Press, Aarhus, p. 389416.

Záveská Drábková, L. \& Kirschner, J. 2013. Oreojuncus, a new genus in the Juncaceae. Preslia 85: 483-503.

\section{LISTA DE EXSICATAS}

Carvalho, A.M. 1061 (3); Conceição, A.S. 385 (3); Fonseca, W.O. 38 (4); Giulietti, A.M. 2529 (4); Guedes, L.M. 11284 (4); Harley, R.M., 15508, 19214 (3), 19648 (4), 20044 (3), 24363, 24984 (4), 26066 (3), 28292, 53581, 54575, 55490 (4), 55514, 55924 (3), CFCR 13350, CFCR 14350 (4), PCD 3112 (2); Hatschbach, G. 46419 , 47394 (3); Irwin, H.S. 31012 (4); Jardim, J. 2541 (4); Mattos Silva, L.A. 4252 (2); Melo, E. 5359, 5867 (4), 10437 (3); Mori, S. 11307 (1), 13156 (3); NicLughadha, E. PCD 5960 (3); Souza, V.C. 26242 (4). 